
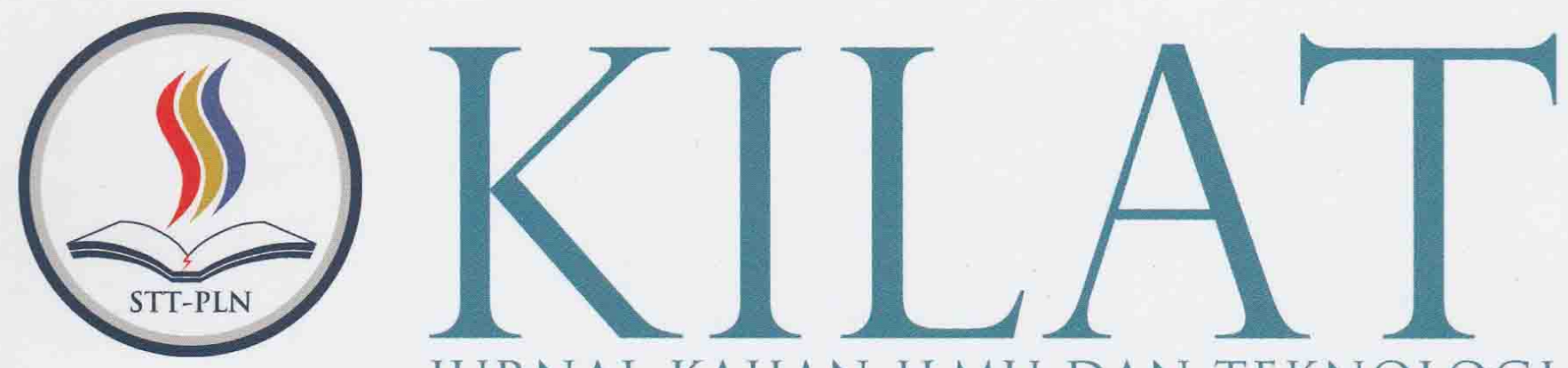
JURNAL KAJIAN ILMU DAN TEKNOLOGI

Dine Tiara Kusuma:

M. Yoga Distra Sudirman: Yessy Fitriani

Emillia; Yuliansyah

Rosida Nur Aziza; Dhzillan Dzhalila

Ranti Hidayawanti

Dewi Arianti Wulandari; Hendra Jatnika; Yudhy S. Purwanto

Rr. Mekar Ageng Kinasti; Endah Lestari; Devita Mayasari

Faisal Piliang

Mauludi Manfaluthy

Pauzi Hasan; Peby Wahyu Purnawan

Rahmi Amir: Baginda Oloan Lubis

Sabar Hanadwiputra; Subandri

Ndaru Ruseno; Satria
PENDEKATAN METODE ALTMAN Z-SCORE DALAM PENENTUAN INSENTIF BONUS PEGAWAI

METODE YURIDIS PENGELOLAAN SAMPAH RUMAH TANGGA DAN SAMPAH SEJENIS DI STT-PLN

METODE KUANTITATIF DENGAN PENDEKATAN KLASIK PADA APLIKASI ANALISIS BUTIR SOAL SEBAGAI MEDIA EVALUASI PENENTUAN SOAL YANG BERKUALITAS

UPAYA TERTIB LISTRIK TERHADAP INSTALATIR KABEL DI DAERAH PADAT PENDUDUK (STUDY KASUS KEC. TAMBORA)

RANCANG BANGUN APLIKASI CLUSTERING DATA MINING MENGGUNAKAN METODE K-MEANS DAN K-MODES

POTENSI PEMANFAATAN LIMBAH PEMBAKARAN BATUBARA (BOTTOM ASH) PADA PLTU SEBAGAI MEDIA TANAM DALAM UPAYA MENGURANGI PENCEMARAN LINGKUNGAN

PEMILIHAN PERANGKAT LUNAK PEMINDAHAN BERKAS DALAM MENINGKATKAN PEMANFAATAN TELEPON PINTAR

PEMANFAATAN RADIASI ENERGI TEGANGAN 150 KV UNTUK LAMPU LED PENERANGAN JALAN

KAJIAN PERBANDINGAN PERFORMANSI ROUTING PROTOCOL RIPNG, OSPFV3 DAN EIGRPVG PADA JARINGAN IPV6

PERANCANGAN PROGRAM PENGELOLAAN DATA KEUANGAN PASIEN RAWAT JALAN BPJS PADA RUMAH SAKIT GRAHA JUANDA BEKASI

ANALISA DAN IMPLEMENTASI VTP DENGAN ETHERCHANNEL TYPE LACP

PENGEMBANGAN RANCANG BANGUN SISTEM KESISWAAN DENGAN MENGGUNAKAN FRAMEWORK MVC

(MODEL VIEW CONTROLLER)

\begin{tabular}{|l|l|l|l|l|l|}
\hline KILAT & VOL.7 & NO.1 & HAL. 1 - 90 & APRIL 2018 & ISSN 2089 - 1245 \\
\hline
\end{tabular}




\title{
PENGEMBANGAN RANCANG BANGUN SISTEM KESISWAAN DENGAN MENGGUNAKAN FRAMEWORK MVC (MODEL VIEW CONTROLLER)
}

\author{
${ }^{1}$ Ndaru Ruseno; ${ }^{2}$ Satria \\ 1)Program Studi/Jurusan Tehnik Informatika, STMIK Bani Saleh, email: ndarumantap@gmail.com \\ 2)Program Studi/Jurusan Sistem Informasi, STMIK Bani Saleh,email: satria1905@gmail.com
}

\begin{abstract}
In the student system requires ease in processing student data and improve the quality of school education. Schools are required to be able and able to make development efforts in terms of school management such as by conducting student administration. So the author makes the design of this student system to be more easily developed and using the pattern of architecture model view controller (MVC). This section of the model is used to define a way in which data can be accessed, the view portion generates output when given data, and the controller receives commands and sets the application for tasks and displays that match the school's wishes. This design prescribes a system development methodology that is with Prototype, with several stages, Stages (1): collecting user needs, where the researcher collects all the necessary data and makes the design the user wants. Stages (2): researchers create a prototype that is by designing temporary designs form. Stage (3): after making prototype then researcher do prototype test for design to be used and result from output required by user. Stages (4): evaluate the system from the design result already made, whether there is any change in the interface form. Stage (5): system usage, where all system is ready to use and according to user wishes. The result of this design is a student system based on all student administration, school curriculum activities and some other data processing.
\end{abstract}

Keywords: System Development, Student, Prototype, Framework, Model View Controller (MVC)

\begin{abstract}
ABSTRAK
Dalam sistem kesiswaan dibutuhkan kemudahan dalam pengolahan data siswa dan meningkatkan mutu pendidikan sekolah. Sekolah dituntut untuk dapat dan mampu melakukan upaya pengembangan dalam hal pengelolaan sekolah seperti dengan melakukan administrasi kesiswaan. Sehingga penulis membuat rancangan sistem kesiswaan ini agar lebih mudah dikembangkan dan menggunakan pola desain berarsitektur model view controller (MVC). Bagian model ini digunakan untukmendefinisikan suatu cara dimana data dapat diakses, bagian view menghasilkan keluaran jika diberikan data, dan bagian controller menerima perintah dan mengatur aplikasi untuk tugas dan tampilan yang sesuai dengan keinginan pihak sekolah. Rancangan ini menerepkan metodologi pengembangan sistem yaitu dengan Prototype, dengan beberapa tahapan, Tahapan (1): mengumpulkan kebutuhan user, dimana peneliti mengumpulkan semua data yang diperlukan dan membuat rancangan yang diinginkan user. Tahapan (2): peneliti membuat prototype yaitu dengan merancangn sementara rancangan-rancangan form. Tahapan(3): setelah membuat prototype maka peneliti melakukan pengujian prototype untuk rancangan yang akan dipakai dan hasil-hasil dari output yang dibutuhkan user. Tahapan (4): melakukan evaluasi sistem dari hasil rancangan yang sudah dibuat, apakah ada perubahan dalam bentuk antarmuka. Tahapan (5): penggunaan sistem, dimana semua sistem sudah siap dipakai dan sesuai keinginan user. Hasil dari rancangan ini adalah sebuah sistem kesiswaan berdasarkan semua administrasikesiswaan, kegiatan kurikulumsekolah dan beberapa pengolahan data lainnya.
\end{abstract}

Kata kunci : Pengembangan Sistem,, Kesiswaan, Prototype, Kerangka kerja, Model View Controller( MVC)

\section{PENDAHULUAN}

Di sekolah penyimpanan data siswa selama ini menggunakan cara manual yaitu menyimpan formulir data siswa yang diisi pada waktu mendaftar sekolah sebagai arsip, karena setiap tahun ada pertambahan siswa maka semakin banyak pula dibutuhkan ruang untuk penyimpanan formulir datasiswa tersebut.Era komputerisasi yang sudah merambah kedunia pendidikan banyakmembuat perubahan dalam segi kegiatan belajar mengajar di sekolah seperti penggunaan presentasi saat mengajar, e-learning, pencaian materi belajar oleh siswa menggunakan internet, pengunaan SPP
Online, penerimaan siswa baru online dan sebagainya.

Dalam hal ini, sekolah membuat sebuah kerangka kerja yaitu sebuah software untuk memudahkan para programmer membuat aplikasi atau web yang isinya adalah berbagai fungsi, plugin, dan konsep sehingga membentuk suatu sistem tertentu. Dengan menggunakan framework, sebuah aplikasi akan tersusun dan terstruktur dengan rapi. Sistem berbasis web telah banyak diterapkan diberbagai bidang, khususnya bagi yang membutuhkan suatu sistem yang bersifat online 
dengan segala kelebihannya, termasuk bidang pendidikan.

Selain itu, metode yang dipakai untuk framework ini maka peneliti memakai model MVC (Model View Controller) yaitu adalah sebuah metode untuk membuat sebuah aplikasi dengan memisahkan data (Model) dari tampilan (View) dan cara bagaimana memprosesnya (Controller). Dalam implementasinya kebanyakan framework dalam aplikasi website adalah berbasis arsitektur MVC karena metode ini sangat memudahkan programmer dalam pembuatan aplikasi sehingga programmer dapat membuat aplikasi dalam waktu yang singkat. Selain itu dengan menerapkan metode Prototype juga dapat memudahkan dalam tahapan pembuatan aplikasi.

Oleh karena itu peneliti menyimpulkan bahwa pihak sekolah harusmembuataplikasi sistem administrasi kesiswaan untuk membantu administrasi kesiswaan dalam menyajikan informasi yang up to date dan informatif. Sehingga dapat membantu pengambilan keputusan yang terbaik.

\section{METODOLOGI PENELITIAN}

\section{Framework}

Menurut Sidik (2012: 1), dengan menggunakan framework, kita tidak perlumembuat program dari awal, tetapi kita sudah diberikan library fungsi-fungsi yang sudahdiorganisasikan untuk dapat membuat suatu program dengan cepat.

Menurut Rosa danShalahuddin (2011: 191), framework merupakan kerangka kerja yang memudahkanprogrammer untuk membuat sebuah aplikasi sehingga programmer akan lebih mudahmelakukan perubahan (customize) terhadap aplikasinya dan dapat memakainya kembaliuntuk aplikasi lain yang sejenis.

\section{Model View Controller (MVC)}

Menurut Sidik (2012: 29 - 30), Model View Controller (MVC) merupakan teknik pemrograman yang popular saat ini, yang mengharapkan pemrogram secara disiplinuntuk membagi program menjadi tiga bagian: model, view dan controller, seperti gambar berikut:

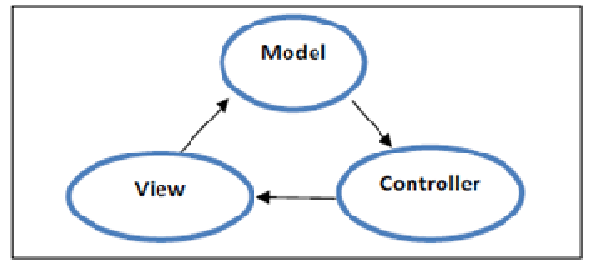

Gambar 1 Model MVC

Keterangan:

1. Model: Merupakan bagian dari aplikasi yang mengimplementasi logika untukdomain data aplikasi.

2. View: Merupakan komponen yang menampilkan antarmuka untuk pengguna (user interface) aplikasi.

3. Controller: Merupakan komponen yang digunakan untuk menangani interaksipengguna, bekerja dengan model, dan memilih view mana yangdigunakan untuk merender data.

Menurut Rosa dan Shalahuddin (2011: 192), konsep Model View Controller (MVC) bertujuan agar sebuah aplikasi dapat mudah diplihara oleh orang-orang di dalam timpengembangan yang berbeda spesifikasi pekerjaan, misalnya database administrator (DBA) untuk mengurusi masalah basis data, blok controller untuk programmer, dan blok viewuntuk desainer antarmuka (interface designer).

Selain itu, MVC memisahkan pengembangan aplikasi berdasarkan komponen utama yang membangun sebuah aplikasi seperti manipulasi data, user interface, dan bagian yang menjadi kontrol aplikasi. Terdapat 3 jenis komponen yang membangun suatu MVC pattern dalam suatu aplikasi yaitu:

- View, merupakan bagian yang menangani presentation logic. Pada suatu aplikasi web bagian ini biasanya berupa file template HTML, yang diatur oleh controller. View berfungsi untuk menerima dan merepresentasikan data kepada user. Bagian ini tidak memiliki akses langsung terhadap bagian model.

- Model, biasanya berhubungan langsung dengan database untuk memanipulasi data (insert, update, delete, search), menangani validasi dari bagian controller, namun tidak dapat berhubungan langsung dengan bagian view.

- Controller, merupakan bagian yang mengatur hubungan antara bagian model dan bagian view, controller berfungsi untuk menerima request dan data dari user kemudian menentukan apa yang akan diproses oleh aplikasi.

Menurut deni Martha dkk (2010), bahwa dengan menggunakan metode MVC tersebut, kode program pada aplikasi tersebut menjadi lebih rapih, karena ada pembagian yang jelas antara masing masing layer/lapisan, akan tetapi waktu yang dibutuhkan dalam pembuatan aplikasi tersebut jauh lebih lama, karena pembuatan aplikasi tersebut dilakukan secara bertahap, mulai dari lapisan Model, View, Controller, serta DAO (Data Access Object).

\section{Tahapan-tahapan Prototype}

Selain itu, untuk memodelkan sebuah perangkat lunak dibutuhkan beberapa tahapan di dalam proses pengembangannya. Tahapan inilah yang akan menentukan keberhasilan dari sebuah softwareitu. Pengembang perangkat lunak harus memperhatikan tahapan dalam metode prototyping agar software finalnya dapat diterima oleh penggunanya. Dan tahapan-tahapan dalam prototyping tersebut adalah sebagai berikut:

\section{Pengumpulan Kebutuhan}

User dan pengembang bersama-sama mendefinisikan format dan kebutuhan kesseluruhan perangkat lunak, 
mengidentifikasikan semua kebutuhan, dan garis besar sistem yang akan dibuat.

\section{Membangun Prototyping}

Membangun prototyping dengan membuat perancangan sementara yang berpusat pada penyajian kepada pelanggan (misalnya dengan membuat input dan contoh outputnya)

\section{Evaluasi protoptyping}

Evaluasi ini dilakukan oleh pelanggan apakah prototyping yang sudah dibangun sudah sesuai dengan keinginan pelanggan. Jika sudah sesuai maka langkah keempat akan diambil. Jika tidak, maka prototyping diperbaiki dengan mengulang langkah 1, 2, dan 3.

\section{Mengkodekan system}

Dalam tahap ini prototyping yang sudah disepakati diterjemahkan ke dalam bahasa pemrograman yang sesuai.

\section{Menguji system}

Setelah sistem sudah menjadi suatu perangkat lunak yang siap pakai, harus dites dahulu sebelum digunakan. Pengujian ini dilakukan dengan White Box, Black Box, Basis Path, pengujian arsitektur dan lain-lain.

\section{Evaluasi Sistem}

User mengevaluasi apakah sistem yang sudah jadi sudah sesuai dengan yang diharapkan .Jika sudah, maka langkah ketujuh dilakukan, jika belum maka mengulangi langkah 4 dan 5 .

\section{Menggunakan Sistem}

Perangkat lunak yang telah diuji dan diterima user siap untuk digunakan.

\section{HASIL DAN ANALISA}

Berdasarkan analisa data yang di peroleh, di SMK Al Muhadjirin 2 ini masih adanya kegiatan yang terlalu lama yaitu masih manualnya dalam melakukan proses administrasi kesiswaan, misalnya pada saat melakukan penilaian kadangkadang proses dari penilaian tersebut terlalu lama dalam pencarian data atau menunggu proses penginputan data yang masih belum di input. Selain itu, dalam keterbukaan nilai masih membahas yang remedial sehingga tidak tahu nilai mereka pada saat ulangan atau ujian, karena dengan terciptanya aplikasi yang akan di bangun ini akan memudahkan siswa untuk mengetahui nilai-nilai yang rendah dan tinggi serta bisa menjadi bahan evaluasi guru untuk menindaklanjuti siswa yang nilainya masih kurang di bawah KKM.

Dari permasalahan diatas seharusnya sekolah memiliki sebuah sistem aplikasi yang bisa membantu semua pekerjaan tentang kesiswaan secara mudah dan efektif. Oleh sebab itu, metode framework MVC dengan menerapkan metode prototype sangat membantu dalam pembuatan aplikasi ini. Dimana aplikasi ini akan membuat peran siswa aktif untuk melihat nilai-nilai yang sudah mereka peroleh dan membantu guru atau walikelas dalam pencarian nilai, serta membantu kurikulum dalam pencetakan absen-absen Ujian serta berita acaranya.

Dari Analisis pengumpulan data yang dilakukan oleh penulis, maka diperoleh bahwa sekolah menargetkan di tahun 2019 sistem informasi pengelolaan akademik khususnya dalam hal: (a) pengelolaan data siswa dan guru, (b) jadwal pelajaran, (c) pengelolaan nilai, (d) serta data kelulusan sudah memanfaatkan perkembangan teknologi informasi dengan lebih baik lagi dari sebelumnya.

\section{Sistem yang Diusulkan}

Berikut gambaran dari sistem diusulkan yang digambarkan dengan menggunakan flowmap:

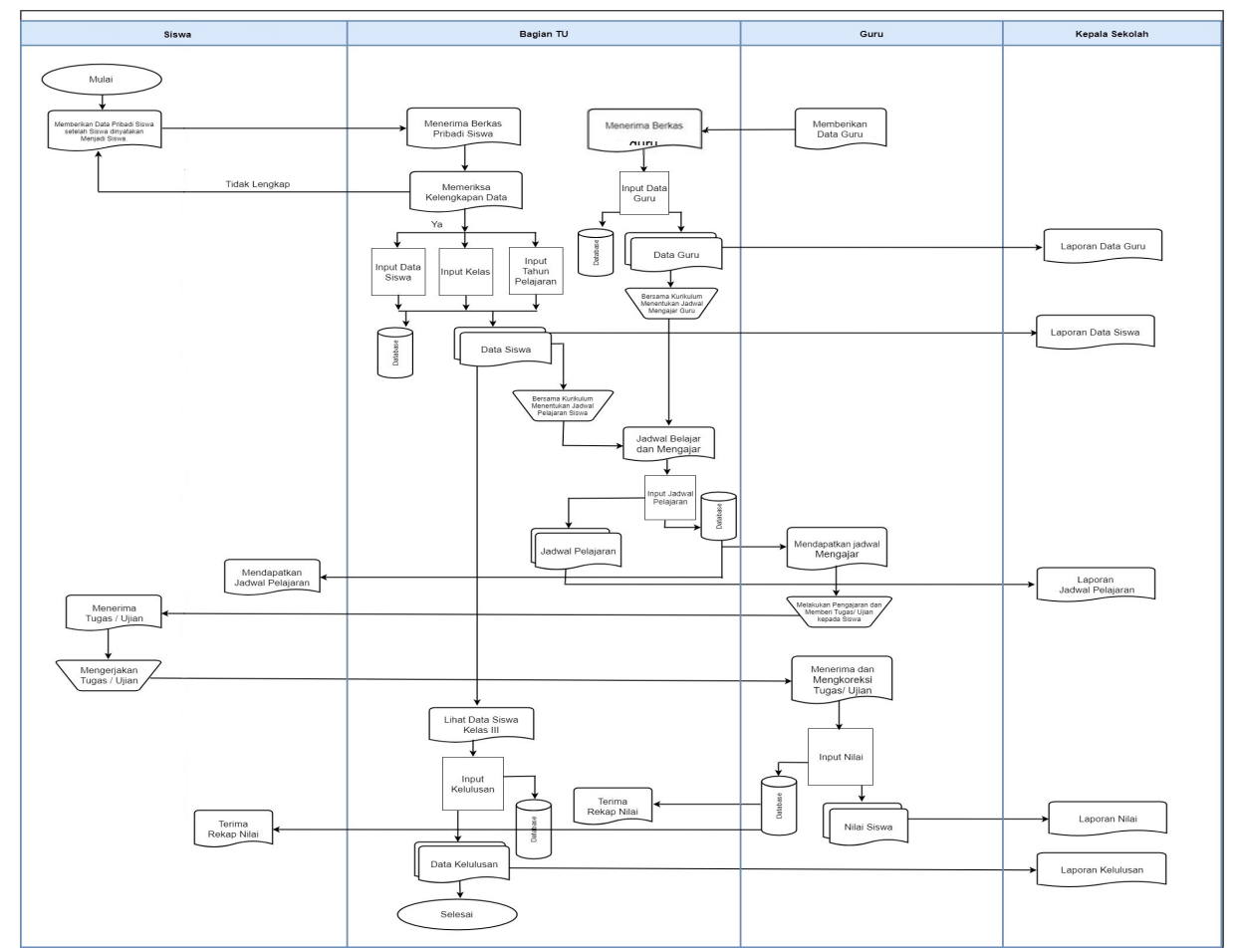

Gambar 2 Sistem Yang Sedang di usulkan 
Berdasarkan analisis yang dilakukan terhadap sistem yang sedang berjalan pada SMK Al Muhadjirin 2 Bekasi mengenai sistem informasi akademik sekolah, penulis memberikan usulan berupa sebuah rancangan sistem informasi akademik.

Dengan dibuatnya sebuah sistem informasi akademik terhadap permasalahan yang ada dapat memberikan kemudahan bagi lingkungan sekolah dalam mendapatkan informasi yang dibutuhkan dan juga dapat memberikan suatu usulan perbaikan bagi sekolah dalam menyediakan informasi khususnya terkait apa yang penulis bahas mulai dari informasi data siswa dan guru, jadwal pelajaran, data nilai, dan juga kelulusan. Adapun sistem yang dibuat nantinya dapat diakses oleh 4 orang seperti siswa, guru, bagian TU, dan juga kurikulum.

Tampilan Implementasi program merupakan sebuah gambaran dari program yang telah dilakukan perancangan sebelumnya. yang mana hasil dari program yang telah di rancang oleh penulis dapat dilihat dibawah ini.

Halaman Home

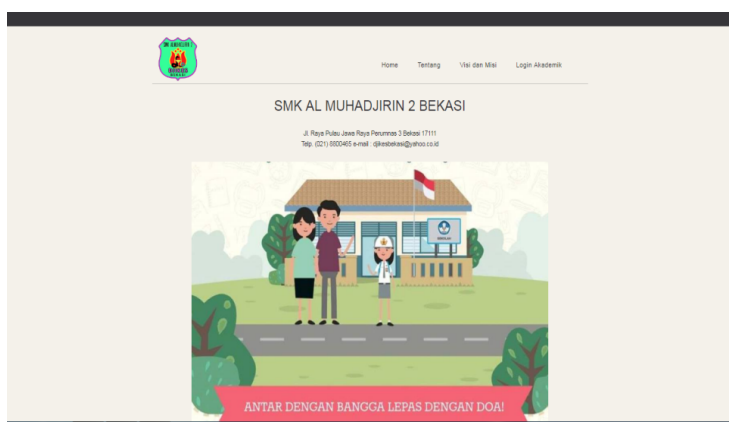

Gambar 3 Halaman Home

Halaman Login

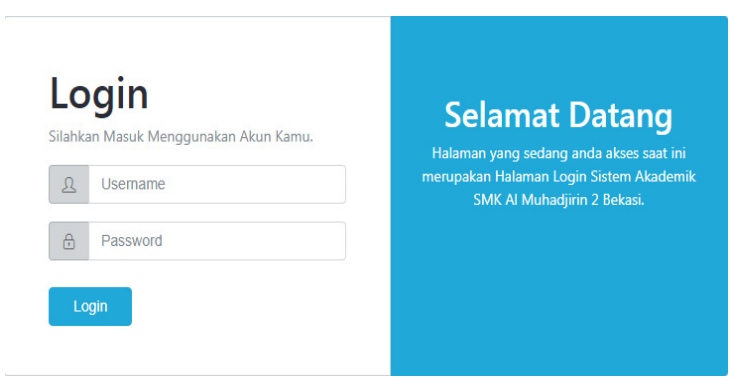

Gambar 4 Halaman Login

Halaman Input Nilai siswa

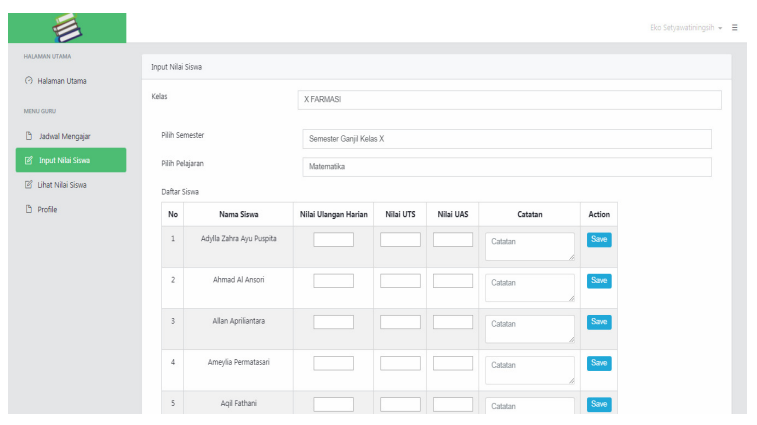

Gambar 5 Input Nilai siswa

Halaman Lihat Nilai siswa

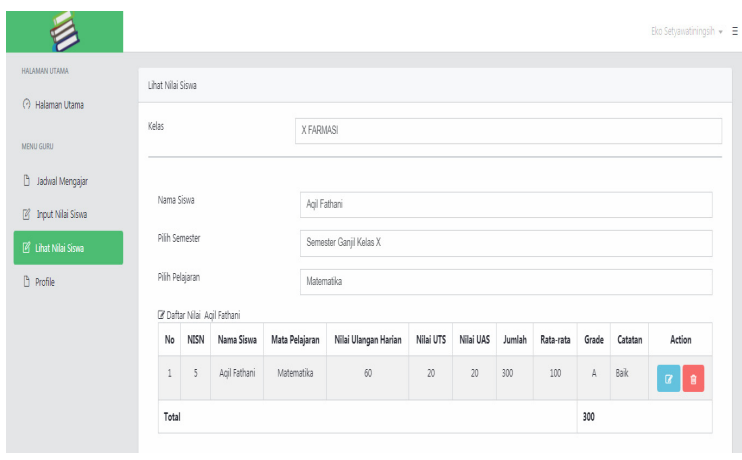

Gambar 6 Lihat Nilai Siswa

Grafik Perkembangan Siswa

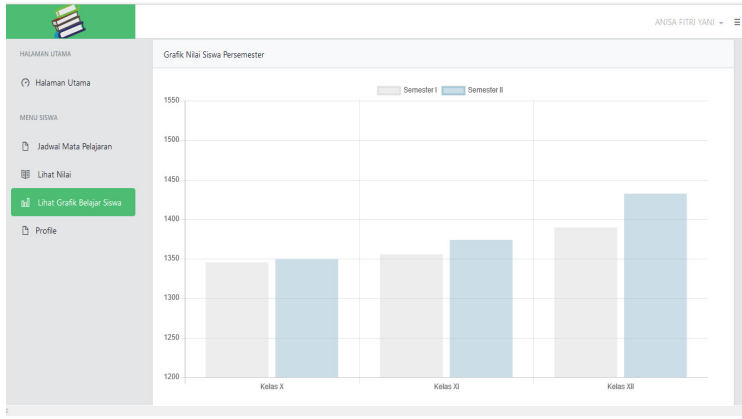

Gambar 7 Grafik Perkembangan siswa

\section{KESIMPULAN}

Berdasarkan dari hasil penelitian dan analisis yang dilakukan pada SMK Al Muhadjirin 2 Bekasi, penulis menyimpulkan sebagai berikut:

a. Sistem Informasi administrasi kesiswaan yang diterapkan di SMK Al Muhadjirin 2 Bekasi dapat mempercepat pencarian data siswa yang meliputi absensi, nilai dan lainnya.

b. Sistem kesiswaan berbasis online dalam lingkungan sekolah, dimana dapat menjadi sarana meningkatkan akreditasi sekolah, meningkatkan kedisplinan dalam pembelajaran. 


\section{SARAN}

Adapun saran yang akan diberikan untuk kedepannya yaitu :

a. Diharapkan aplikasi ini dapat membantu pihak sekolah dalam pengolahan data siswa

b. Diharapkan pihak SMK Al Muhadjirin 2 Bekasi dapat mengimplementasikan aplikasi ini, agar dapat mendukung kegiatan sekolah sebagaimana mestinya.

\section{DAFTAR PUSTAKA}

\section{JURNAL}

Deni Martha dkk. Metode MVC untuk Perancangan Sistem Berorientasi Objek pada Ujian Saringan Masuk Penerimaan Mahasiswa Baru di STMIK CIC Cirebon. Vol 6, No 2 (2010).

Imam Solikin. Perancangan Sistem Infomasi Penjualan Berbasis Framework Model View Controller (MVC) Pada Pt Thamrin Brother Cabang Oki. Jurnal Media Informatika Dan Komputer Vol. 4 No.1 Desember 2014.

\section{BUKU}

Betha, Sidik, Ir. Agustus 2004. Pemrograman WEB dengan PHP. Informatika, Bandung.

Fathansyah.2010. Basis Data. Informatika Bandung, Bandung.

H.M, Jogiyanto. 2005.Analisis dan Design Sistem Informasi : Pendekatan Terstruktur Teori dan Praktek Apilkasi Bisnis. Penerbit : Andi Offset, Yogyakarta.

Rosa A.S dan M.Shalahuddin. 2011. Modul Pembelajaran Rekayasa Perangkat Lunak(Terstruktur dan Berorientasi Objek., Bandung.

Sidik, Betha, 2012, Framework Codeigniter. Penerbit Infomatika, Bandung 